Prepared for the U.S. Department of Energy under Contract DE-AC05-76RL01830

\title{
Climate Science for a Sustainable Energy Future Atmospheric Radiation Measurement Best Estimate (CSSEFARMBE)
}

LD Riihimaki K Gaustad

SA McFarlane

September 2012

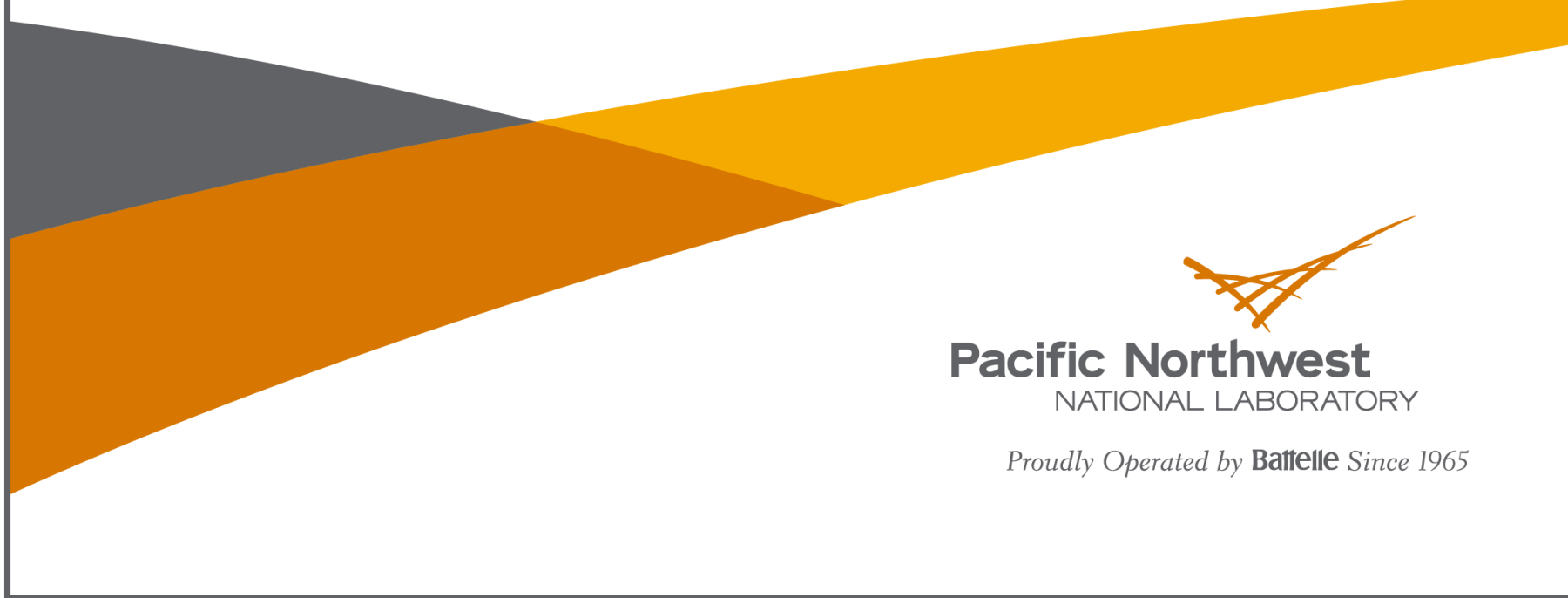




\section{DISCLAIMER}

This report was prepared as an account of work sponsored by an agency of the United States Government. Neither the United States Government nor any agency thereof, nor Battelle Memorial Institute, nor any of their employees, makes any warranty, express or implied, or assumes any legal liability or responsibility for the accuracy, completeness, or usefulness of any information, apparatus, product, or process disclosed, or represents that its use would not infringe privately owned rights. Reference herein to any specific commercial product, process, or service by trade name, trademark, manufacturer, or otherwise does not necessarily constitute or imply its endorsement, recommendation, or favoring by the United States Government or any agency thereof, or Battelle Memorial Institute. The views and opinions of authors expressed herein do not necessarily state or reflect those of the United States Government or any agency thereof

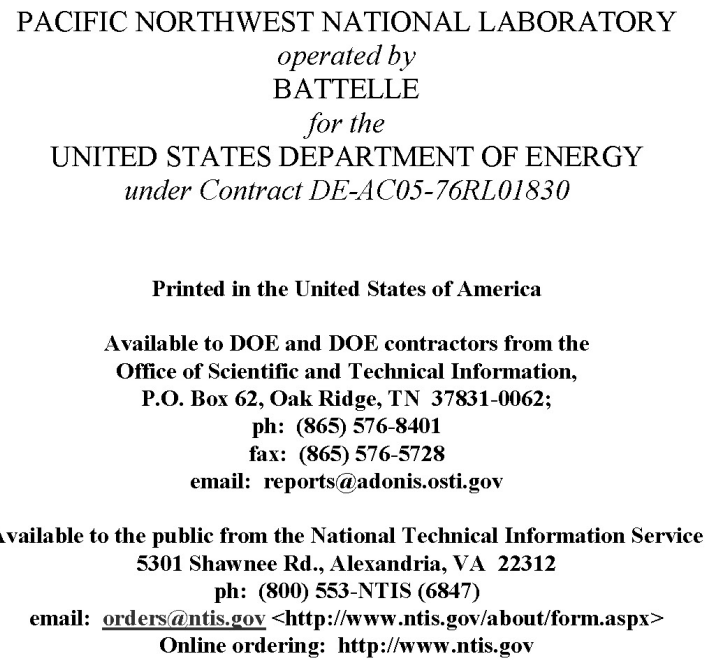

This document was printed on recycled paper. 


\title{
Climate Science for a Sustainable Energy Future Atmospheric Radiation Measurement Best Estimate (CSSEFARMBE)
}

\author{
LD Riihimaki \\ SA McFarlane \\ K Gaustad
}

September 2012

Prepared for

the U.S. Department of Energy

under Contract DE-AC05-76RL01830

Pacific Northwest National Laboratory

Richland, Washington 99352 



\section{Acknowledgments}

CSSEFARMBE was created under the Department of Energy (DOE) Climate Science for a Sustainable Energy Future (CSSEF) project, which is supported by DOE's Climate and Earth System Modeling (CESM) Program. The development of CSSEFARMBE benefited from discussions with others in the CSSEF project, particularly scientists in the atmospheric data and uncertainty quantification groups. Observational data is from the DOE Atmospheric Radiation Measurement (ARM) program. We are grateful for the help and expertise of Shaocheng Xie and Renata McCoy who developed the ARM Best Estimate (ARMBE) Value Added Product (VAP) upon which the CSSEFARMBE data set is based, shared their code, expertise, and time in discussing the data. Many thanks also to Mike Ritsche and Jenni Prell for their work maintaining the ARM surface meteorological data set and sharing their expertise about instrument uncertainty. Claude Duchon graciously shared data from a field rain gauge comparison that we used to estimate the magnitude of the uncertainty caused by wind effects. 



\section{Contents}

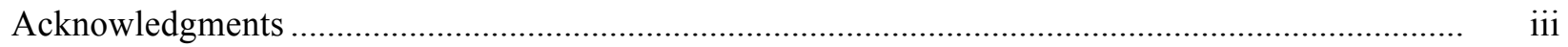

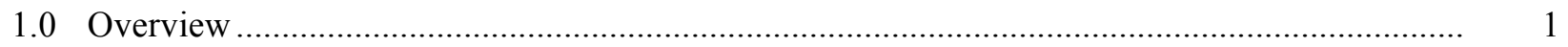

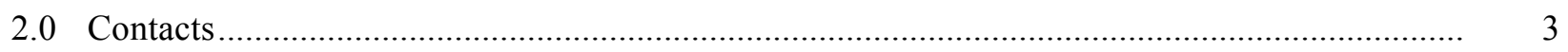

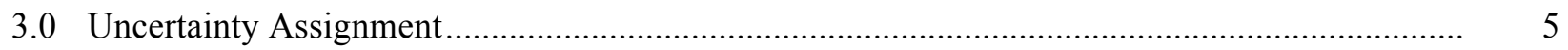

3.1 Addition of Error Fields...................................................................................... 5

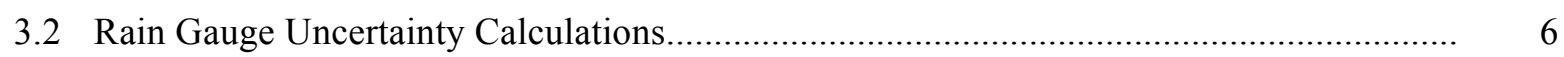

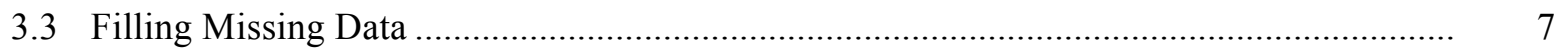

4.0 Differences Between CSSEFARMBE and ARMBE …....................................................... 11

4.1 Statistical Comparison Between CSSEFARMBE and ARMBE Data................................... 12

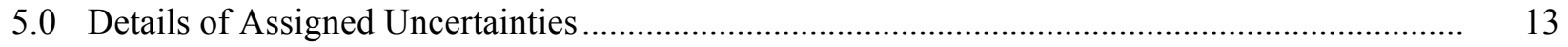

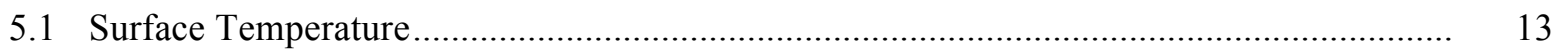

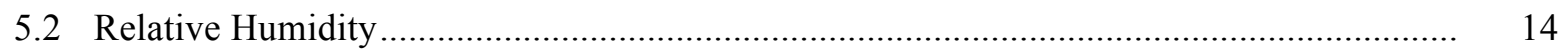

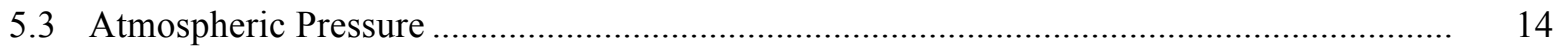

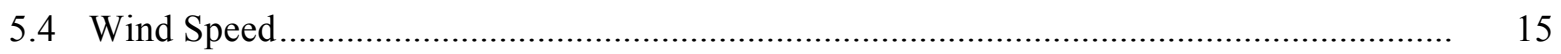

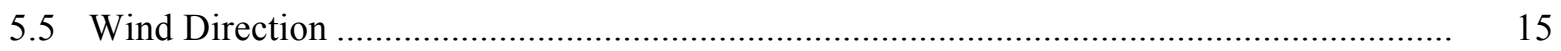

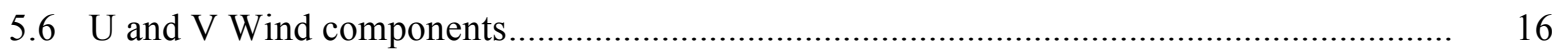

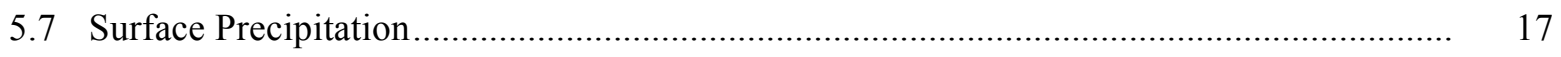

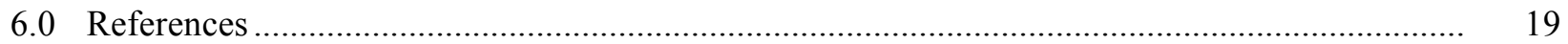




\section{Figures}

Figure 1. Example diagnostic plots using CSSEFARMBE observations and uncertainties.

Figure 2. Scatter plot of total precipitation measured by an unshielded rain gauge and a rain gauge in a pit as reference.

Figure 3. Annual average (black) and standard deviation (blue) of the difference between observed temperature and temperature filled in by linear interpolation for a given minute of the day. Each panel shows the results for the center time period when an interval of 20,60, or 120 consecutive minutes (as labeled) were filled using linear interpolation.

Figure 4. The average standard deviation of the difference between observed and filled data for a given number of consecutive missing minutes (black o's). Red lines show regression fits to these values, as described by the equations in Table 2 .

Figure 5. Difference between precipitation values from ARMBE and CSSEFARMBE data sets (blue) are caused by a different choice of precipitation variables. Precipitation rates from ARMBE data (red) are also plotted for reference.

\section{Tables}

Table 1. Random errors assigned to each filled data point for a given number of consecutive missing minutes $(N)$.

Table 2. Statistics of differences between ARMBE and CSSEFARMBE hourly average variables

Table 3. SGP Central Facility (E13), Temperature Uncertainty

Table 4. SGP Extended Facilities, Temperature Uncertainty

Table 5: SGP Facilities, RH Uncertainty

Table 6. SGP Facilities, Atmospheric Pressure Uncertainty

Table 7. SGP Facilities, Wind Speed Uncertainty....

Table 8. Wind Direction Alignment Correction

Table 9. SGP Facilities, Wind Direction Uncertainty

Table 10. SGP Facilities, Rain Gauge Uncertainties. 


\subsection{Overview}

The Climate Science for a Sustainable Energy Future (CSSEF) project is working to improve the representation of the hydrological cycle in global climate models, critical information necessary for decision-makers to respond appropriately to predictions of future climate. In order to accomplish this objective, CSSEF is building testbeds to implement uncertainty quantification (UQ) techniques to objectively calibrate and diagnose climate model parameterizations and predictions with respect to local, process-scale observations. In order to quantify the agreement between models and observations accurately, uncertainty estimates on these observations are needed.

The DOE Atmospheric Radiation Measurement (ARM) program takes atmospheric and climate related measurements at three permanent locations worldwide. The ARM VAP called the ARM Best Estimate (ARMBE) [Xie et al., 2010] collects a subset of ARM observations, performs quality control checks, averages them to one hour temporal resolution, and puts them in a standard format for ease of use by climate modelers. ARMBE has been widely used by the climate modeling community as a summary product of many of the ARM observations. However, the ARMBE product does not include uncertainty estimates on the data values. Thus, to meet the objectives of the CSSEF project and enable better use of this data with UQ techniques, we created the CSSEFARMBE data set.

For the current implementation of CSSEFARMBE, only a subset of the variables contained in ARMBE is included in CSSEFARMBE. CSSEFARMBE currently consists of only surface meteorological observations, though this may be expanded to include other variables in the future. The CSSEFARMBE VAP is focused on the ARM Southern Great Plains (SGP) site, and is produced for all extended facilities at SGP that contain surface meteorological equipment. This extension of the ARMBE data set to multiple facilities at SGP allows for better comparison between model grid boxes and the ARM point observations. In the future, CSSEFARMBE may also be created for other ARM sites. As each site has slightly different instrumentation, this will require additional development to understand the uncertainty characterization associated with instrumentation at those sites.

The uncertainty assignment process is implemented into the ARM program's new Integrated Software Development Environment (ISDE) so that many of the key steps can be used in the future to screen data based on ARM Data Quality Reports (DQRs), propagate uncertainties when transforming data from one time scale into another, and convert names and units into NetCDF Climate and Forecast (CF) standards. These processes are described in more detail in the following sections. 



\title{
2.0 Contacts
}

\author{
Laura Riihimaki \\ Scientist \\ Atmospheric Sciences and Global Change Division \\ Pacific Northwest National Laboratory \\ P.O. Box 999, MSIN K9-24 \\ Richland, WA 99352 \\ Ph: (509) 3756406 \\ laura.riihimaki@pnnl.gov
}

Krista Gaustad

Software Engineer

Scientific Data Management

Pacific Northwest National Laboratory

P.O. Box 999, MSIN K7-28

Richland, WA 99352

Ph: (509) 3755950

krista.gaustad@pnnl.gov 



\subsection{Uncertainty Assignment}

\subsection{Addition of Error Fields}

The primary purpose of creating the CSSEFARMBE data set is to add uncertainty estimates to the already widely used ARMBE data. To accomplish this, errors are assigned to the one-minute resolution data based on instrument specifications and field conditions, then propagated to hourly averages. Three new fields are added to the output file for each variable of interest to characterize the error estimates on that variable: random error, positive systematic error, and negative systematic error.
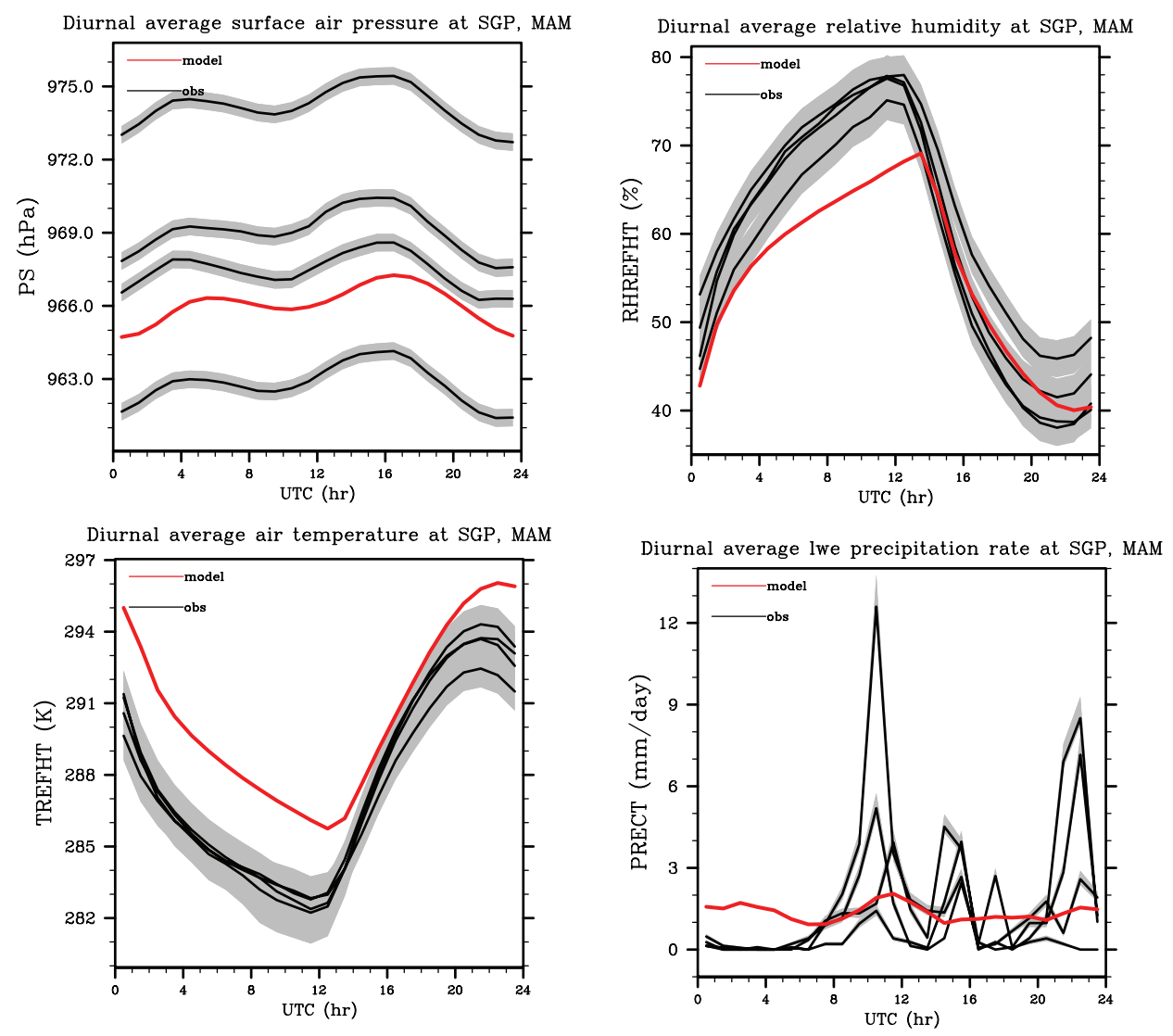

Figure 1. Example diagnostic plots using CSSEFARMBE observations and uncertainties.

Systematic and random errors are propagated using standard procedures. Systematic errors assigned to one-minute data are averaged to give hourly average systematic error estimates. Random errors are added in quadrature using the following standard formula: $\sigma_{h r}=\sqrt{\sigma_{\min }^{2} / N}$. By keeping track of systematic and random errors separately, errors can be propagated accurately to other averages of interest, for example, the composite diurnal cycle plots shown in Figure 1. To create the gray, 95 percent confidence interval envelopes around each observational data set, propagated systematic and random errors are added in quadrature and multiplied by two (errors are reported as one standard deviation or equivalent) using the following standard formulas: 


$$
\begin{aligned}
& X_{\text {upper }}=X_{\text {obs }}+2 \cdot \sqrt{\sigma_{\text {rand }}^{2}+\sigma_{\text {pos sys err }}^{2}} \\
& X_{\text {lower }}=X_{\text {obs }}-2 \cdot \sqrt{\sigma_{\text {rand }}^{2}+\sigma_{\text {neg sys err }}^{2}}
\end{aligned}
$$

Where $X_{\text {obs }}$ represents a particular measurement like temperature and $\sigma_{\text {rand, }} \sigma_{\text {pos sys err }}, \sigma_{\text {neg sys err }}$ are its respective uncertainties. The details of the error assigned to each variable are described in section 5.0. Bias errors are either corrected or recorded as systematic errors.

\subsection{Rain Gauge Uncertainty Calculations}

Because precipitation is of particular interest to the CSSEF project, special attention was paid to the rain gauge uncertainty assignments. Accurate rain gauge measurements are more difficult to make than other surface meteorological data. Our method of uncertainty assignment accounts for several known biases in rain gauge observations. First, we use the corrected value of precipitation from the ARM met data set (the current ARM standard data set for meteorological observations), which corrects for biases that correspond to the rain rate. Individual tipping-bucket rain gauges are calibrated using a dynamic calibration method [Humphrey et al., 1997] to correct for nonlinear instrument response to rain rate.

One of the largest biases in rain gauge measurements is the under catch of precipitation due to nonlinear wind effects. This bias is particularly large with solid precipitation like snow that drifts considerably. Accurate corrections for solid precipitation errors would be a significant undertaking and would require more information than is available. Because the CSSEF program is focusing on precipitation in the warm season at SGP, we chose to simply assign a 50 percent bias uncertainty to any precipitation measurements when the temperature was below zero as an indicator that these measurements are highly uncertain. To assess wind bias errors in rain precipitation events we used data from an experiment comparing unshielded rain gauges to reference rain gauges placed in a pit to avoid loss due to wind [Duchon and Essenberg, 2001]. Claude Duchon provided us with total rain amount from both gauges for 103 precipitation events over a period of two and a half years at a location in Oklahoma near the ARM SGP site. Figure 2 shows a scatter plot of those 103 data points from the two gauges. A linear regression fit to these data, constrained to include the origin, shows an average 4.4 percent negative bias due to wind effects. This should be a conservative estimate of the bias at the SGP site since the precipitation gauges are shielded at these facilities. In addition to the 4.4 percent bias, we included the standard error of the slope coefficient ( 0.6 percent) as a random error in the uncertainty to account for the spread of the values around the linear regression fit. 


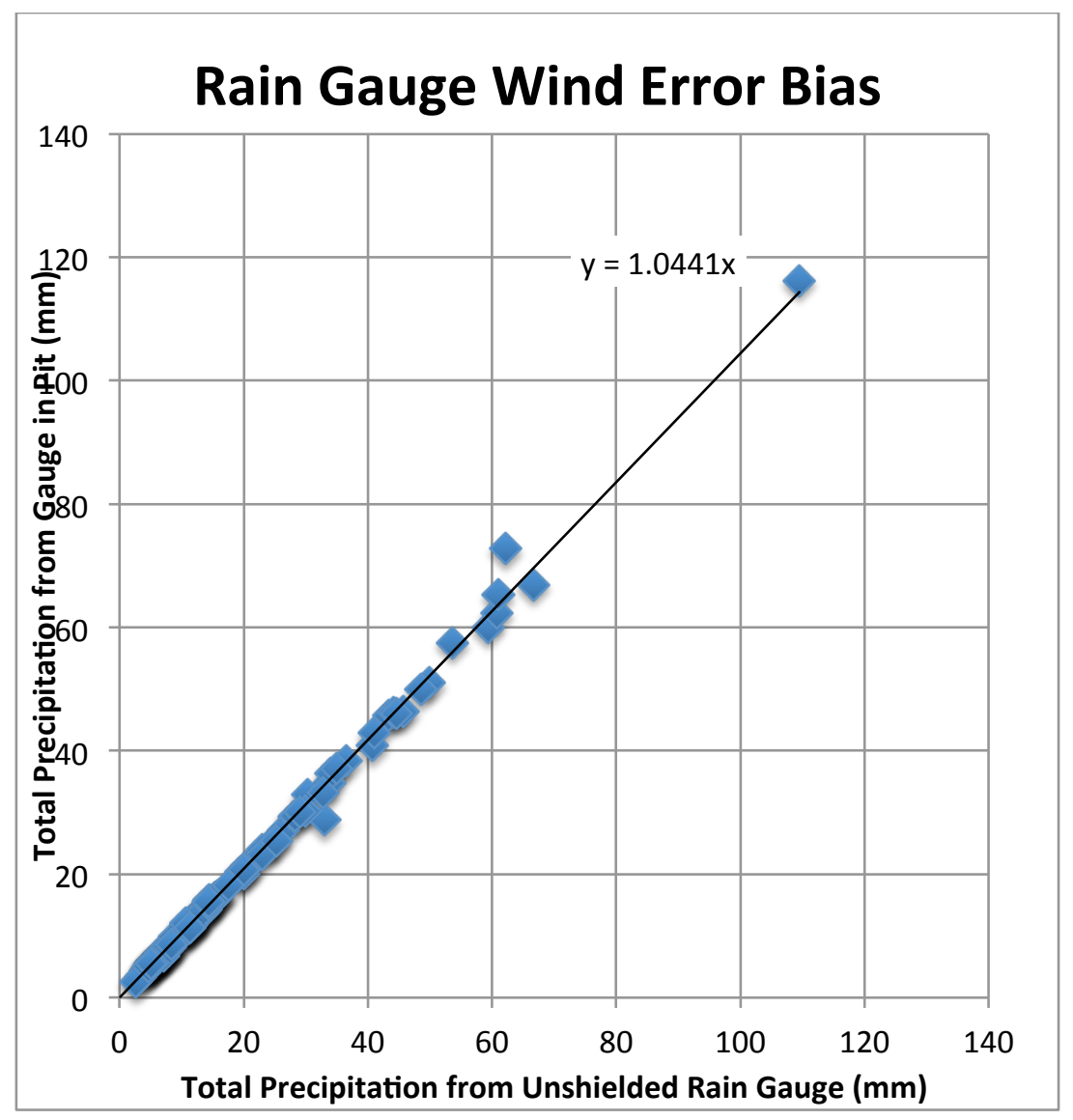

Figure 2. Scatter plot of total precipitation measured by an unshielded rain gauge and a rain gauge in a pit as reference.

In addition to the bias corrections, we included a random error to account for local variability effects. This is not strictly an instrument uncertainty, but rather an uncertainty for how representative the observation is for the surrounding area. It has been found that even rain gauges in close proximity (on the order of meters) measure different amounts of rainfall due to high local variability in rain rate. We used equation 5 from the study by Ciach [2003] and read the coefficients from the plots in Figure 6 to calculate this uncertainty. This is a random error and will be less important when averaging over long time scales.

\subsection{Filling Missing Data}

When fewer than 120 consecutive minutes were missing in some variables, these data were filled using linear interpolation between the last good measurements on either side of the time gap. An error was then associated with each filled datum based on the number of consecutive minutes missing using the equations given in Table 1. This was done for most (temperature, $\mathrm{RH}$, atmospheric pressure, $\mathrm{u}$ and $\mathrm{v}$ components of wind, arithmetic mean wind speed), but not all, surface meteorological variables. Missing precipitation data was not filled due to the rapidly varying and on/off nature of precipitation data. 


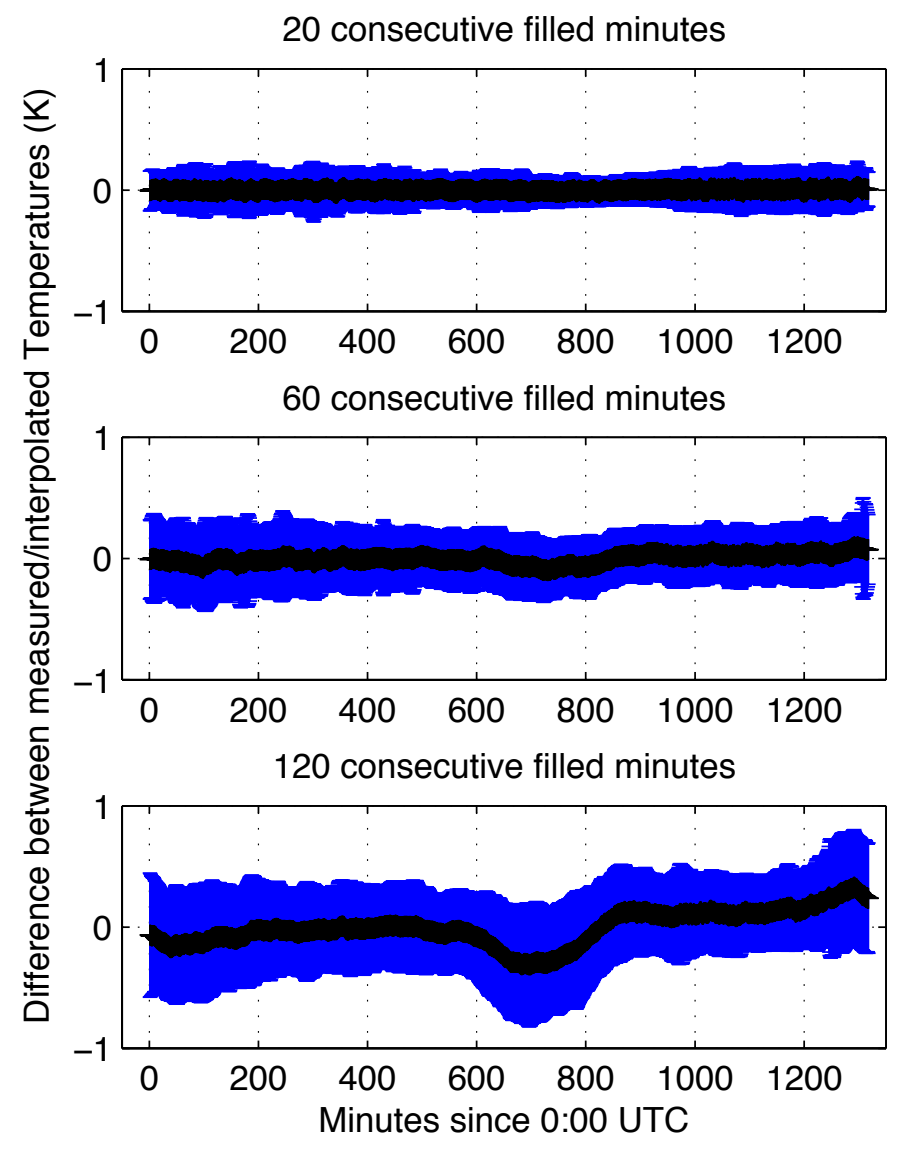

Figure 3. Annual average (black) and standard deviation (blue) of the difference between observed temperature and temperature filled in by linear interpolation for a given minute of the day. Each panel shows the results for the center time period when an interval of 20,60, or 120 consecutive minutes (as labeled) were filled using linear interpolation.

To assign an uncertainty to each filled minute, observations were artificially removed from complete data sets and then comparisons were done between original data and filled data. An example is shown for temperature in Figure 3. A given interval of observational data centered on each minute during all days in 2011 was removed and filled by linear interpolation, and the difference between the original and the filled data point was calculated. The year 2011 was chosen because it is a year of interest to the project and because the observations are relatively complete during that year. It is assumed that calculating the uncertainty of filled data from one year is representative of the full time period of data since inter-annual variability is not likely to cause greater differences than the seasonal or diurnal cycle. The standard deviation of that difference over all days in the year for a given time is shown in each point in Figure 3 (blue). Each panel shows this calculation for a different interval of consecutive missing days, with the error getting larger with an increase in the number of missing days. For the sake of simplicity, we assume that the error caused by filling missing data is the same for all times and is normally distributed around the true value. Though this assumption is not perfect, it is reasonable based on the relatively small deviation of the black points from the $\mathrm{y}=0$ line in Figure 3 and similar magnitudes of the blue error bars surrounding them. Missing periods greater than 120 minutes were not filled because this assumption is no longer a good approximation. 

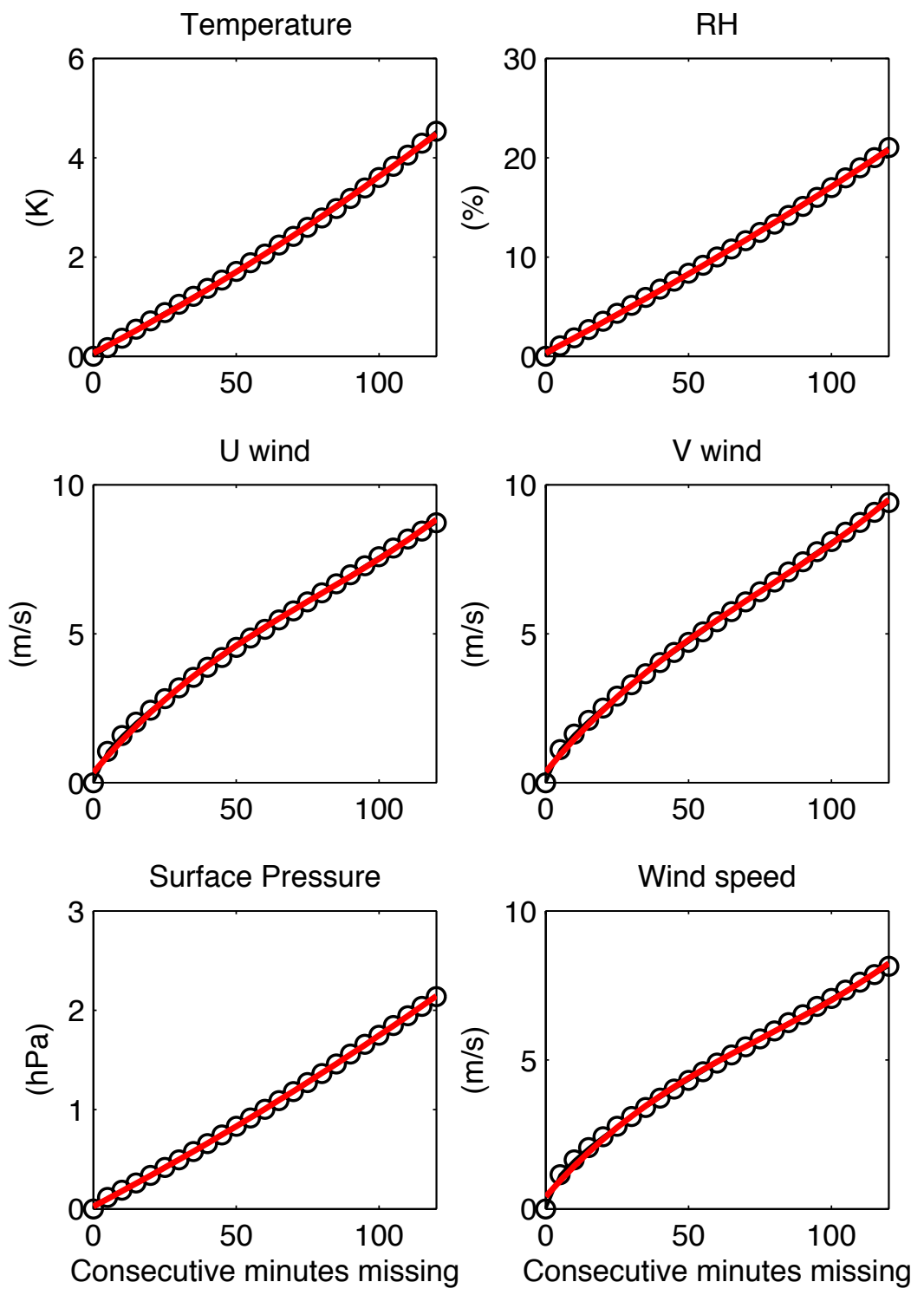

Figure 4. The average standard deviation of the difference between observed and filled data for a given number of consecutive missing minutes (black o's). Red lines show regression fits to these values, as described by the equations in Table 2 .

Thus, for each given interval of number of missing days, the average of all standard deviations for each minute is calculated. That is, the mean of all blue points in each panel in Figure 3 becomes the estimate of the error of a one-minute data point filled by linear interpolation for a given interval of missing minutes. These errors are plotted in black circles in Figure 4 for a range of intervals of missing minutes between 0 and 120. The resulting least-squares regression fits (Figure 4, red lines) to these deviations are the basis of the random errors assigned to data when filled by interpolation, and are listed as formulas in Table 1. 
Table 1. Random errors assigned to each filled data point for a given number of consecutive missing minutes $(N)$.

\begin{tabular}{lc}
\hline Temperature & $\sigma_{\text {rand }}=5.84 \cdot 10^{-5} \cdot N^{2}+0.0298 \cdot N+0.0639$ \\
Relative Humidity & $\sigma_{\text {rand }}=0.00016 \cdot N^{2}+0.151 \cdot N+0.325$ \\
Atmospheric Pressure & $\sigma_{\text {rand }}=2.12 \cdot 10^{-5} \cdot N^{2}+0.0151 \cdot N+0.0249$ \\
U Wind Component & $\sigma_{\text {rand }}=3.11 \cdot 10^{-6} \cdot N^{3}-0.000737 \cdot N^{2}+0.114 \cdot N+0.345$ \\
V Wind Component & $\sigma_{\text {rand }}=3.09 \cdot 10^{-6} \cdot N^{3}-0.000701 \cdot N^{2}+0.116 \cdot N+0.37$ \\
Wind Speed (arith mean) & $\sigma_{\text {rand }}=3.41 \cdot 10^{-6} \cdot N^{3}-0.000784 \cdot N^{2}+0.110 \cdot N+0.409$ \\
\hline
\end{tabular}




\subsection{Differences Between CSSEFARMBE and ARMBE}

The error assignment was done in ARM's new ISDE to take advantage of the system's features such as automated addition of DQR flags, transformations of data, ease of metadata creation, and standard name assignment. This feature required rewriting the quality assessment and processing of ARMBE from Interactive Data Language (IDL) into the C programming language as ISDE only supported development in $\mathrm{C}$ at the time of data set creation.

In addition to the use of ISDE, the CSSEFARMBE processing differs from ARMBE in several other ways. First, the CSSEFARMBE creates hourly averages from 1-minute surface meteorological data from the ARM MET or Surface Meteorological Observation System (SMOS) data streams rather than from the 30-minute SMOS data products used in ARMBE prior to September 2009. Creating averages from the higher resolution data allows more accurate assignment of uncertainties that depend on the instantaneous values of the observations. Second, within the CSSEF project, a new automated feature was developed for ISDE to read in ARM DQRs and assign quality flags accordingly. We used this information to eliminate data that was flagged as bad in DQRs. ARMBE data is manually checked for errors, which we did not repeat, replacing this instead with the automated DQR process. Third, we used the corrected surface precipitation variable "tbrg_total_precip_corr" from the ARM MET data sets, as opposed to the original precipitation variable used by the ARMBE VAP. The corrected precipitation can have substantially different values than the original precipitation variable as shown in Figure 5 (blue line), these differences are about 25 percent of the total precipitation values at the SGP central facility in 2008 . Finally, we chose to fill missing data by interpolation when less than 120 consecutive minutes were missing, as described in section 3.3.

To characterize the impact of these choices on the CSSEFARMBE surface meteorological data, we compare it to the ARMBE data and give a summary of the results in the remainder of this section.

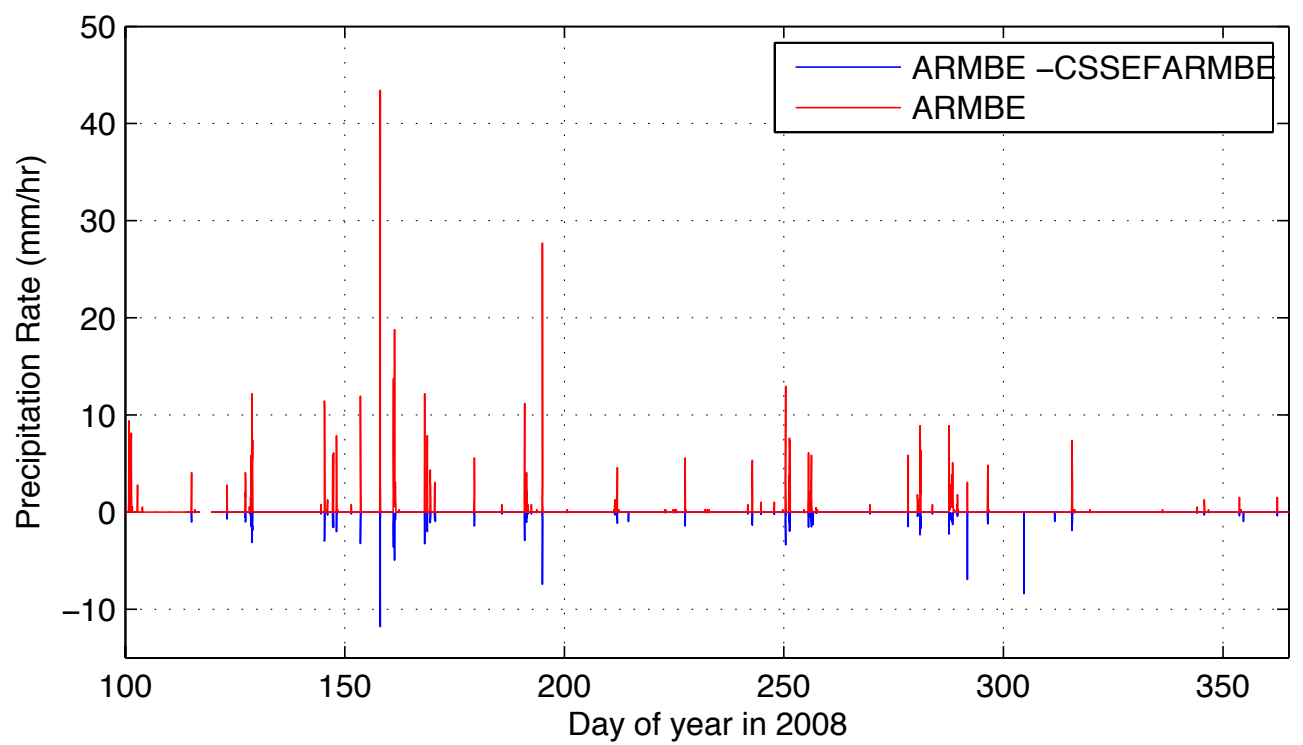

Figure 5. Difference between precipitation values from ARMBE and CSSEFARMBE data sets (blue) are caused by a different choice of precipitation variables. Precipitation rates from ARMBE data (red) are also plotted for reference. 


\subsection{Statistical Comparison Between CSSEFARMBE and ARMBE Data}

To examine the impact of the processing changes, we calculated statistics for the difference between variables in the CSSEFARMBE and ARMBE data sets. To do this comparison we used version 1.3a of the ARMBE data set, downloaded from the ARM archive in August 2012. There appears to be a difference in the time interval used in the hour averages between the two data sets after September 2009 when the ARM SMOS data set is no longer available and ARMBE uses the one-minute met data instead. We are in discussion with the developers of the ARMBE data set about how to best resolve this discrepancy, but for the purposes of this comparison we restrict our statistical analysis to data from 1994 to August 2009. The precipitation comparisons are only available from March 2008-August 2009 because the met data does not yet have corrected precipitation earlier than 2008 .

Table 2 shows that there is good agreement between ARMBE and CSSEFARMBE data sets for most variables, with the exception of precipitation and wind direction. The higher percentage of precipitation data points with greater than 1 or 10 percent differences is caused by the different choice of precipitation variables described earlier in this section. There are two causes of the discrepancy in wind direction values between the two data sets: a correction for a bias and a difference in the way wind direction is averaged. As described in section 5.5, wind direction is corrected for biases due to misalignment from true North. At E13, that difference is 3 degrees, causing all ARMBE values to be greater than 1 percent higher than CSSEFARMBE data. In addition, however, we believe there may be a bug in the averaging process of the ARMBE data set that does not correctly calculate the "modal" average, a value that wraps around from 360 to 0 degrees. We are in communication with the developers of the ARMBE data set to confirm this and anticipate that this discrepancy will be fixed in future versions of the ARMBE data set.

Table 2. Statistics of differences between ARMBE and CSSEFARMBE hourly average variables.

\begin{tabular}{lllll}
\hline Variable & $\begin{array}{l}\text { Mean } \\
\text { difference }\end{array}$ & $\begin{array}{l}\text { RMS } \\
\text { difference }\end{array}$ & \multicolumn{2}{l}{ Percentage of data points with differences: } \\
\cline { 4 - 5 } & $0.0001 \mathrm{~K}$ & $0.03 \mathrm{~K}$ & $0 \%$ & $>\mathbf{1 0 \%}$ \\
\hline Temperature & $-0.001 \%$ & $0.07 \%$ & $0.01 \%$ & $0.003 \%$ \\
\hline Relative Humidity & $-0.002 \mathrm{hPa}$ & $0.03 \mathrm{hPa}$ & $0 \%$ & $0.1 \%$ \\
\hline Surface Pressure & $0.1^{\circ}$ & $38^{\circ}$ & $11 \%$ & $0 \%$ \\
\hline Wind Direction & $0.002 \mathrm{~m} / \mathrm{s}$ & $0.1 \mathrm{~m} / \mathrm{s}$ & $0.08 \%$ & $87 \%$ \\
\hline Wind Speed (arith) & $-0.03 \mathrm{~mm} / \mathrm{hr}$ & $0.3 \mathrm{~mm} / \mathrm{hr}$ & $56 \%$ & $0.2 \%$ \\
\hline Precipitation & &
\end{tabular}




\subsection{Details of Assigned Uncertainties}

\subsection{Surface Temperature}

Instrument: Campbell Scientific HMP35C

Units: ${ }^{\circ} \mathrm{C}$

References: [Ritsche, 2008]

Algorithm notes: All known uncertainties were assigned as systematic errors based on the assumption that this basic uncertainty comes from calibration/accuracy limitations and does not decrease with averaging.

Table 3. SGP Central Facility (E13), Temperature Uncertainty

\begin{tabular}{lllll}
\hline & Description & Neg. Sys. Error & Pos. Sys. Error & Random Error \\
\hline Baseline uncertainty & $\begin{array}{l}\text { Includes sensor } \\
\text { interchangeability, bridge } \\
\text { resistor precision, polynomial } \\
\text { curve fitting errors }\end{array}$ & $0.2^{\circ} \mathrm{C}$ & $0.2^{\circ} \mathrm{C}$ & $0^{\circ} \mathrm{C}$ \\
Conditional uncertainty & $\begin{array}{l}\text { Uncertainty due to radiation: } \\
\text { For an aspirated radiation } \\
\text { shield (used only at central } \\
\text { facility) uncertainty is } \\
\text { constant }\end{array}$ & $0.1^{\circ} \mathrm{C}$ & $0.1^{\circ} \mathrm{C}$ & $0^{\circ} \mathrm{C}$ \\
\hline $\begin{array}{l}\text { Not known, not thought to be } \\
\text { large between calibrations }\end{array}$ & $0^{\circ} \mathrm{C}$ & $0^{\circ} \mathrm{C}$ & 0 \\
\hline Sensor Drift & & $0.29^{\circ} \mathrm{C}$ & $0.29^{\circ} \mathrm{C}$ & $0^{\circ} \mathrm{C}$ \\
\hline Total: & &
\end{tabular}

Table 4. SGP Extended Facilities, Temperature Uncertainty

\begin{tabular}{|c|c|c|c|c|}
\hline & Description & $\begin{array}{l}\text { Neg. Sys. } \\
\text { Error }\end{array}$ & $\begin{array}{l}\text { Pos. Sys. } \\
\text { Error }\end{array}$ & Random Error \\
\hline $\begin{array}{l}\text { Baseline } \\
\text { uncertainty }\end{array}$ & $\begin{array}{l}\text { Includes sensor interchangeability, } \\
\text { bridge resistor precision, polynomial } \\
\text { curve fitting errors }\end{array}$ & $0.2^{\circ} \mathrm{C}$ & $0.2^{\circ} \mathrm{C}$ & $0^{\circ} \mathrm{C}$ \\
\hline \multirow[t]{5}{*}{$\begin{array}{l}\text { Conditional } \\
\text { uncertainty }\end{array}$} & $\begin{array}{l}\text { Uncertainty due to radiation depends on } \\
\text { wind speed for naturally aspirated } \\
\text { radiation shield: }\end{array}$ & & & \\
\hline & $\mathrm{WS}>=6 \mathrm{~m} / \mathrm{s}$ & $0.1^{\circ} \mathrm{C}$ & $0.1^{\circ} \mathrm{C}$ & $0^{\circ} \mathrm{C}$ \\
\hline & $3 \mathrm{~m} / \mathrm{s}<=\mathrm{WS}<6 \mathrm{~m} / \mathrm{s}$ & $0.4^{\circ} \mathrm{C}$ & $0.4^{\circ} \mathrm{C}$ & $0^{\circ} \mathrm{C}$ \\
\hline & $2 \mathrm{~m} / \mathrm{s}<=\mathrm{WS}<3 \mathrm{~m} / \mathrm{s}$ & $0.7^{\circ} \mathrm{C}$ & $0.7^{\circ} \mathrm{C}$ & $0^{\circ} \mathrm{C}$ \\
\hline & $\mathrm{WS}<2 \mathrm{~m} / \mathrm{s}$ & $1.5^{\circ} \mathrm{C}$ & $1.5^{\circ} \mathrm{C}$ & $0^{\circ} \mathrm{C}$ \\
\hline Sensor Drift & $\begin{array}{l}\text { Not known, not thought to be large } \\
\text { between calibrations }\end{array}$ & $0^{\circ} \mathrm{C}$ & $0^{\circ} \mathrm{C}$ & $0^{\circ} \mathrm{C}$ \\
\hline \multirow[t]{4}{*}{ Total: } & $\mathrm{WS}>=6 \mathrm{~m} / \mathrm{s}$ & $0.23^{\circ} \mathrm{C}$ & $0.23^{\circ} \mathrm{C}$ & $0^{\circ} \mathrm{C}$ \\
\hline & $3 \mathrm{~m} / \mathrm{s}<=\mathrm{WS}<6 \mathrm{~m} / \mathrm{s}$ & $0.45^{\circ} \mathrm{C}$ & $0.45^{\circ} \mathrm{C}$ & $0^{\circ} \mathrm{C}$ \\
\hline & $2 \mathrm{~m} / \mathrm{s}<=\mathrm{WS}<3 \mathrm{~m} / \mathrm{s}$ & $0.73^{\circ} \mathrm{C}$ & $0.73^{\circ} \mathrm{C}$ & $0^{\circ} \mathrm{C}$ \\
\hline & $\mathrm{WS}<2 \mathrm{~m} / \mathrm{s}$ & $1.54^{\circ} \mathrm{C}$ & $1.54^{\circ} \mathrm{C}$ & $0^{\circ} \mathrm{C}$ \\
\hline
\end{tabular}




\subsection{Relative Humidity}

Instrument: Campbell Scientific HMP35C

Units: \%

References: [Ritsche, 2008]

Algorithm notes: All known uncertainties were assigned as systematic errors based on the assumption that this basic uncertainty comes from calibration/accuracy limitations and does not decrease with averaging.

Table 5: SGP Facilities, RH Uncertainty.

\begin{tabular}{|c|c|c|c|c|}
\hline & Description & $\begin{array}{l}\text { Neg. Sys. } \\
\text { Error }\end{array}$ & Pos. Sys. Error & Random Error \\
\hline \multirow[t]{3}{*}{ Manufacturer Specs } & $\begin{array}{l}\text { Includes calibration } \\
\text { uncertainty, repeatability, } \\
\text { hysteresis, temperature } \\
\text { dependence, and long-term } \\
\text { stability over a period of one } \\
\text { year }\end{array}$ & & & \\
\hline & $\mathrm{RH}<90 \%$ & $1.03 \%$ & $1.03 \%$ & $0 \%$ \\
\hline & $\mathrm{RH}>=90 \%$ & $1.52 \%$ & $1.52 \%$ & $0 \%$ \\
\hline \multirow[t]{2}{*}{ Total: } & $\mathrm{RH}<90 \%$ & $1.03 \%$ & $1.03 \%$ & $0 \%$ \\
\hline & $\mathrm{RH}>=90 \%$ & $1.52 \%$ & $1.52 \%$ & $0 \%$ \\
\hline
\end{tabular}

\subsection{Atmospheric Pressure}

Instrument: Digital barometer, Vaisala Model PTB201A

Units: hPa

References: [Ritsche, 2008]

Algorithm notes: All known uncertainties were assigned as systematic errors based on the assumption that this basic uncertainty comes from calibration/accuracy limitations and does not decrease with averaging.

Table 6. SGP Facilities, Atmospheric Pressure Uncertainty

\begin{tabular}{lllll}
\hline & Description & $\begin{array}{l}\text { Neg. Sys. } \\
\text { Error }\end{array}$ & $\begin{array}{l}\text { Pos. Sys. } \\
\text { Error }\end{array}$ & $\begin{array}{l}\text { Random } \\
\text { Error }\end{array}$ \\
\hline Manufacturer's specs & $\begin{array}{l}\text { Includes linearity, } \\
\text { hysteresis, calibration } \\
\text { uncertainty, repeatability, } \\
\text { temperature dependence, } \\
\text { long-term stability over a } \\
\text { year }\end{array}$ & $0.18 \mathrm{hPa}$ & $0.18 \mathrm{hPa}$ & $0 \mathrm{hPa}$ \\
& & & \\
\hline Total: & & $0.18 \mathrm{hPa}$ & $0.18 \mathrm{hPa}$ & $0 \mathrm{hPa}$ \\
\hline
\end{tabular}




\subsection{Wind Speed}

Instrument: R. M. Young Model 05103 Wind Monitor

Units: $\mathrm{m} / \mathrm{s}$

References: [Ritsche, 2008]

Algorithm notes: These uncertainties are assigned to both arithmetic mean and vector mean wind speeds at one-minute resolution. Wind speeds must be above $1.0 \mathrm{~m} / \mathrm{s}$ to be detected by the instrument. The possible bias error due to wind speeds below detection threshold is not corrected for, but is included in the systematic errors given in Table 5. The negative values for "positive systematic errors" in Table 5 represent situations where the range of possible biases is negative.

Table 7. SGP Facilities, Wind Speed Uncertainty

\begin{tabular}{|c|c|c|c|c|}
\hline & Description & Neg. Sys. Error & Pos. Sys. Error & Random Error \\
\hline Baseline uncertainty & NIST calibration uncertainty & $0 \mathrm{~m} / \mathrm{s}$ & $0 \mathrm{~m} / \mathrm{s}$ & WS*0.01 \\
\hline \multirow[t]{6}{*}{ Conditional uncertainty } & $\begin{array}{l}\text { Uncertainty due to possible } \\
\text { wind speeds below detection } \\
\text { threshold of } 1.0 \mathrm{~m} / \mathrm{s}\end{array}$ & & & \\
\hline & $\mathrm{WS}<1.0$ & $0.51 \mathrm{~m} / \mathrm{s}$ & $-0.49 \mathrm{~m} / \mathrm{s}$ & \\
\hline & $1.0<=\mathrm{WS}<1.5$ & $0.31 \mathrm{~m} / \mathrm{s}$ & $-0.20 \mathrm{~m} / \mathrm{s}$ & \\
\hline & $1.5<=\mathrm{WS}<2.0$ & $0.22 \mathrm{~m} / \mathrm{s}$ & $0 \mathrm{~m} / \mathrm{s}$ & \\
\hline & $2.0<=\mathrm{WS}<2.5$ & $0.12 \mathrm{~m} / \mathrm{s}$ & $0.02 \mathrm{~m} / \mathrm{s}$ & \\
\hline & $\mathrm{WS}>=2.5$ & $0 \mathrm{~m} / \mathrm{s}$ & $0 \mathrm{~m} / \mathrm{s}$ & \\
\hline \multirow[t]{5}{*}{ Total: } & $\mathrm{WS}<1.0$ & $0.51 \mathrm{~m} / \mathrm{s}$ & $-0.49 \mathrm{~m} / \mathrm{s}$ & WS*0.01 \\
\hline & $1.0<=\mathrm{WS}<1.5$ & $.31 \mathrm{~m} / \mathrm{s}$ & $-0.20 \mathrm{~m} / \mathrm{s}$ & WS*0.01 \\
\hline & $1.5<=\mathrm{WS}<2.0$ & $0.22 \mathrm{~m} / \mathrm{s}$ & $0 \mathrm{~m} / \mathrm{s}$ & WS*0.01 \\
\hline & $2.0<=\mathrm{WS}<2.5$ & $0.12 \mathrm{~m} / \mathrm{s}$ & $0.02 \mathrm{~m} / \mathrm{s}$ & WS*0.01 \\
\hline & $\mathrm{WS}>=2.5$ & $0 \mathrm{~m} / \mathrm{s}$ & $0 \mathrm{~m} / \mathrm{s}$ & $\mathrm{WS} * 0.01$ \\
\hline
\end{tabular}

\subsection{Wind Direction}

Instrument: R. M. Young Model 05103 Wind Monitor

Units: ${ }^{\circ}$

References: [Ritsche, 2008]

Algorithm notes: Biases in wind direction from tower misalignment are corrected in the CSSEFARMBE dataset. The corrections in Table 6 are added to the wind direction data at a given site. The values are based on the deviations from true North given in Table 7 of the SMOS Handbook. 
Table 8. Wind Direction Alignment Correction

\begin{tabular}{lr}
\hline Site & Bias Correction \\
\hline E1 & $-1^{\circ}$ \\
E3 & $-2^{\circ}$ \\
E5 & $+2^{\circ}$ \\
E6 & $-4^{\circ}$ \\
E7 & $-1^{\circ}$ \\
E9 & $+2^{\circ}$ \\
E11 & $+2^{\circ}$ \\
E13 & $+3^{\circ}$ \\
E15 & $+1^{\circ}$ \\
E20 & $-1^{\circ}$ \\
E24 & $+3^{\circ}$ \\
E27 & $-6^{\circ}$ \\
\hline
\end{tabular}

Table 9. SGP Facilities, Wind Direction Uncertainty

\begin{tabular}{|c|c|c|c|c|}
\hline & Description & Neg. Sys. Error & Pos. Sys. Error & Random Error \\
\hline Manufacturer specs & $\begin{array}{l}\text { Includes sensor accuracy, A/D } \\
\text { conversion accuracy, }\end{array}$ & $0^{\circ}$ & $0^{\circ}$ & $2.5^{\circ}$ \\
\hline Total: & & $0^{\circ}$ & $0^{\circ}$ & $2.5^{\circ}$ \\
\hline
\end{tabular}

\subsection{U and V Wind components}

Instrument: R. M. Young Model 05103 Wind Monitor

Units: $\mathrm{m} / \mathrm{s}$

References: [Ritsche, 2008]

Algorithm notes: $\mathrm{U}$ and $\mathrm{V}$ Wind components are calculated from vector averaged wind speed and wind direction measurements. The errors of the $u$ and $v$ wind speeds are similarly calculated from the errors of wind speed and wind direction as given in the equations below:

Random errors:

$$
\begin{aligned}
& \text { uwind }_{\text {rand err }}=\sqrt{\sin ^{2}(\text { wdir }) \cdot w s p d_{\text {rand err }}+w \operatorname{spd}^{2} \cos ^{2}(\text { wdir }) w d i r_{\text {rand } \text { err }}^{2}} \\
& \text { vwind }_{\text {rand err }}=\sqrt{\cos ^{2}(w d i r) \cdot w s p d_{\text {rand err }}+w \operatorname{spd}^{2} \sin ^{2}(w d i r) w d i r_{\text {rand } \text { err }}^{2}}
\end{aligned}
$$

Systematic errors:

$$
\begin{aligned}
& \text { uwind }_{\text {neg sys err }}=w s p d_{\text {neg sys err }} \sqrt{\sin ^{2}(w d i r)} \\
& \text { uwind }_{\text {pos sys err }}=w s p d_{\text {pos sys err }} \sqrt{\sin ^{2}(w d i r)} \\
& \text { vwind }_{\text {neg sys err }}=w s p d_{\text {neg sys err }} \sqrt{\cos ^{2}(w d i r)} \\
& \text { vwind }_{\text {pos sys err }}=w s p d_{\text {pos sys err }} \sqrt{\cos ^{2}(w d i r)}
\end{aligned}
$$




\subsection{Surface Precipitation}

Instrument: Electrically heated, tipping-bucket precipitation gauge, Novalynx Model 260-2500E-12

Rain/Snow Gauge

Units: $\mathrm{mm} / \mathrm{hr}$

References: [Ciach, 2003; Duchon and Essenberg, 2001; Goodison et al., 1998; Humphrey et al., 1997;

Ritsche, 2008]

Algorithm notes: Bias error due to undercatch of precipitation from wind as described below in section 4.7.1. An additional random error is included based on the study by Ciach (2003) that found variation in measurements between multiple rain gauges in close proximity.

Table 10. SGP Facilities, Rain Gauge Uncertainties

\begin{tabular}{|c|c|c|c|c|}
\hline & Description & Neg. Sys. Error & $\begin{array}{l}\text { Pos. Sys. } \\
\text { Error }\end{array}$ & Random Error \\
\hline \multirow{3}{*}{$\begin{array}{l}\text { Uncertainty due to } \\
\text { wind (based on data } \\
\text { from Duchon and } \\
\text { Essenberg 2001) }\end{array}$} & $\begin{array}{l}\text { Error due to undercatch of } \\
\text { precipitation from wind }\end{array}$ & & & \\
\hline & Temperature $<=0$ & $0.5 *$ precip & $0 \mathrm{~mm} / \mathrm{hr}$ & $0 \mathrm{~mm} / \mathrm{hr}$ \\
\hline & Temperature $>0$ & $0.044 *$ precip & $0 \mathrm{~mm} / \mathrm{hr}$ & precip*.006 \\
\hline $\begin{array}{l}\text { Local variability } \\
\text { (from Ciach 2003) }\end{array}$ & & $0 \mathrm{~mm} / \mathrm{hr}$ & $0 \mathrm{~mm} / \mathrm{hr}$ & $\begin{array}{l}\mathrm{e}_{0}=0.07 \\
\mathrm{R}_{0}=6 \mathrm{~mm} / \mathrm{hr} \\
\mathrm{e}_{0}+\mathrm{R}_{0} / \mathrm{precip}\end{array}$ \\
\hline \multirow[t]{2}{*}{ Total: } & Temperature $<=0$ & $0.5 *$ precip & $0 \mathrm{~mm} / \mathrm{hr}$ & $\mathrm{e}_{0}+\mathrm{R}_{0} /$ precip \\
\hline & Temperature $>0$ & $0.044 *$ precip & $0 \mathrm{~mm} / \mathrm{hr}$ & $\begin{array}{l}\operatorname{Sqrt}\left(\left(\mathrm{e}_{0}+\right.\right. \\
\left.\mathrm{R}_{0} / \text { precip }\right)^{2}+ \\
\left.\left(\text { precip* }^{*} .006\right)^{2}\right)\end{array}$ \\
\hline
\end{tabular}





\subsection{References}

Ciach GJ. 2003. "Local Random Errors in Tipping-Bucket Rain Gauge Measurements." Journal of Atmospheric and Oceanic Technology, 20(5):752-759.

Duchon CE and GR Essenberg. 2001. "Comparative Rainfall Observations from Pit and Aboveground Rain Gauges with and without Wind Shields." Water Resources Research, 37(12):3253-3263.

Goodison BE, PYT Louie, and DQ Yang. 1998. "WMO Solid Precipitation Measurement Intercomparison.” Rep. WMO/TD No. 872, 212 pp. World Meteorological Organization, Geneva.

Humphrey MD, JD Istok, JY Lee, JA Hevesi, and AL Flint. 1997. “A New Method for Automated Dynamic Calibration of Tipping-Bucket Rain Gauges." Journal of Atmospheric and Oceanic Technology, 14(6):1513-1519.

Ritsche MT. 2008. "Surface Meteorological Observation System (SMOS) Handbook." Report DOE/SCARM/TR-031, U.S. Department of Energy.

Xie SC, RB McCoy, SA Klein, RT Cederwall, WJ Wiscombe, MP Jensen, KL Johnson, EE Clothiaux, KL Gaustad, CN Long, JH Mather, SA McFarlane, J-CG Golaz, Y Lin, SD Hall, RA McCord, G Palanisamy, DD Turner. 2010. "ARM Climate Modeling Best Estimate Data, A New Data Product for Climate Studies." Bulletin of the American Meteorological Society, 91(1):DOI 10.1175/2009bams2891.1. 


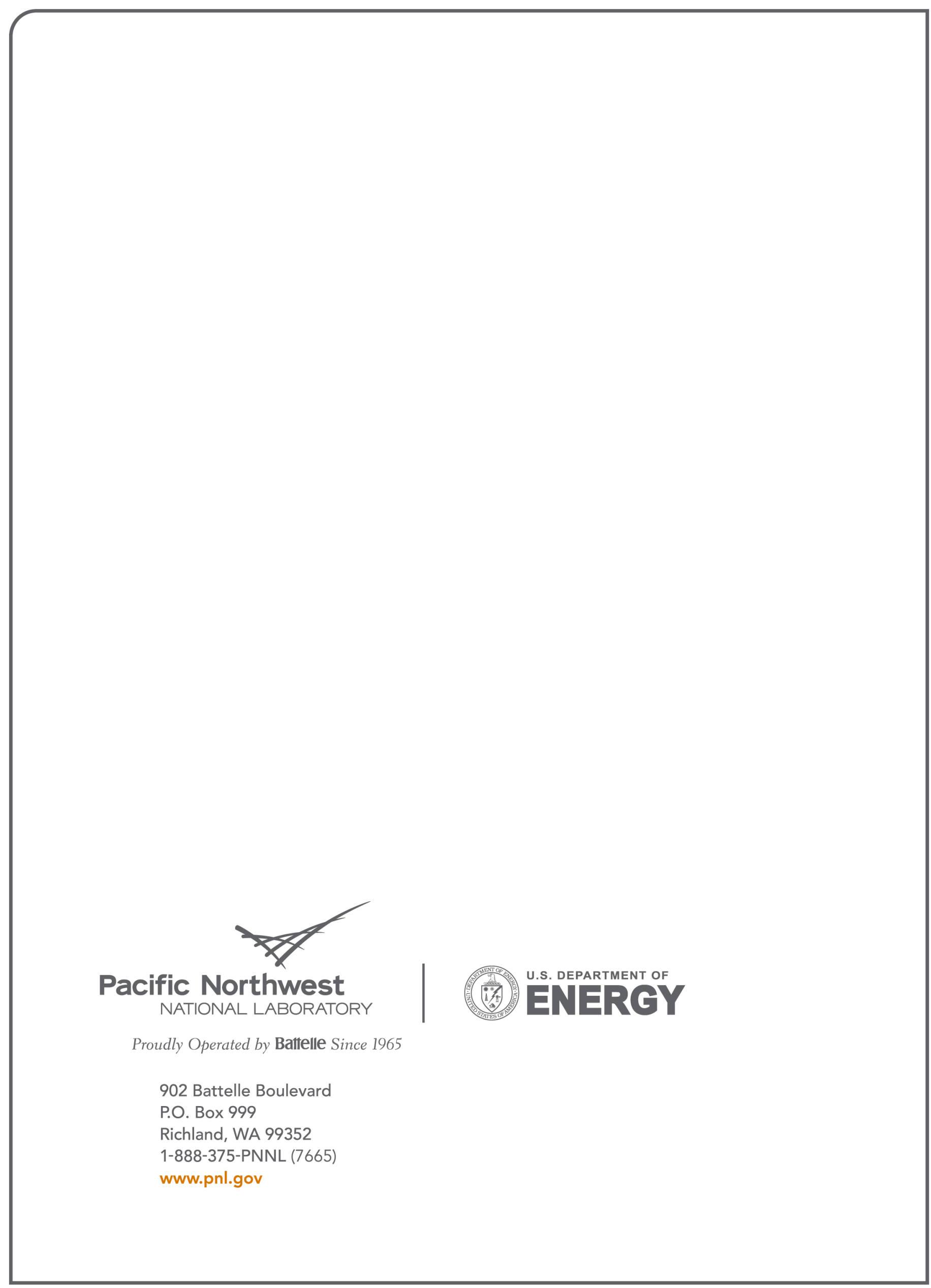

